\title{
ENDOCRINE TUMOURS
}

\section{Imaging in the follow-up of differentiated thyroid cancer: current evidence and future perspectives for a risk-adapted approach}

\author{
Livia Lamartina ${ }^{1}$, Désirée Deandreis ${ }^{2}$, Cosimo Durante ${ }^{1}$ and Sebastiano Filetti ${ }^{1}$ \\ ${ }^{1}$ Department of Internal Medicine and Medical Specialties, University of Rome Sapienza, Rome, Italy, \\ ${ }^{2}$ Department of Nuclear Medicine and Endocrine Oncology, Gustave Roussy and University Paris Saclay, \\ Villejuif, France
}

Correspondence should be addressed to S Filetti

Email

sebastiano.filetti@uniroma1.it

\begin{abstract}
The clinical and epidemiological profiles of differentiated thyroid cancers (DTCs) have changed in the last three decades. Today's DTCs are more likely to be small, localized, asymptomatic papillary forms. Current practice is, though, moving toward more conservative approaches (e.g. lobectomy instead of total thyroidectomy, selective use of radioiodine). This evolution has been paralleled and partly driven by rapid technological advances in the field of diagnostic imaging. The challenge of contemporary DTCs follow-up is to tailor a risk-of-recurrence-based management, taking into account the dynamic nature of these risks, which evolve over time, spontaneously and in response to treatments. This review provides a closer look at the evolving evidence-based views on the use and utility of imaging technology in the post-treatment staging and the short- and long-term surveillance of patients with DTCs. The studies considered range from cervical US with Doppler flow analysis to an expanding palette of increasingly sophisticated second-line studies (cross-sectional, functional, combined-modality approaches), which can be used to detect disease that has spread beyond the neck and, in some cases, shed light on its probable outcome.
\end{abstract}

\section{Introduction}

The clinical and epidemiological profiles of differentiated thyroid cancers (DTCs) have evolved remarkably over the past 30 years. In the 1980s and 1990s, patients usually presented with palpable primaries, often accompanied by locoregional or even distant metastases $(1,2)$. Today's
DTCs are more likely to be small, localized, asymptomatic papillary forms, many with subcentimeter diameters (3). These changes have been paralleled and in large part driven by advances in diagnostic imaging technology. Since the late 1980s, clinicians' toolboxes for examining

\section{Invited Author's profile}

Sebastiano Filetti, MD, is a full professor of Internal Medicine and Dean of the Faculty of Medicine and Dentistry at Sapienza - University of Rome, Rome, Italy. Prof. Filetti's current clinical interests include endocrine and thyroid cancer, diabetes, and endocrine/metabolic diseases. In particular, his clinical and research interests are focused on the management of thyroid nodule and advanced thyroid cancer. Thyroid tumorigenesis and the implications of the genetic and epigenetic abnormalities in thyroid cancer are also Prof. Filetti's research interests.

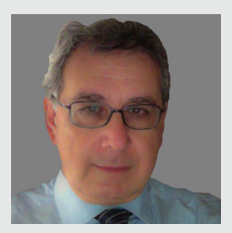

() 2016 European Society of Endocrinology Printed in Great Britain
Published by Bioscientifica Ltd. 
the interior of the human body have expanded rapidly to include gray-scale ultrasonography (US), Doppler flow analysis, computed tomography (CT), magnetic resonance imaging (MRI), and positron emission tomography (PET). Widespread clinical use of these new techniques for assessing structures in the head and neck (e.g. carotid arteries) has been responsible for the incidental discovery of many of the tiny, silent thyroid cancers being diagnosed and treated today $(4,5,6)$.

The evolving profile of DTCs has been mirrored by changes in our approaches to their treatment and follow-up. The standard of care before the 2000s involved total thyroidectomy (often with neck dissection), liberal use of radioiodine remnant ablation (RRA), and life-long surveillance based chiefly on whole-body radioiodine scintigraphy (WBS) and serum thyroglobulin (Tg) assays. Support is now growing for more conservative strategies in selected cases: lobectomy, omission of RRA, even active surveillance alone, which is now an option for some papillary microcarcinomas $(7,8,9)$. These changes, too, have been facilitated by the availability of new imaging tools and techniques. The frequent use in the past of aggressive treatments (e.g. total thyroidectomy followed by RRA) was dictated in part by the need to eradicate not only the neoplastic thyroid tissue but normal thyroid remnants as well, since their uptake of iodine and production of thyroglobulin diminished the diagnostic performance of WBS and Tg assays during postoperative surveillance. These constraints were attenuated by increasing reliance on US surveillance, freeing clinicians to consider more individualized treatments for DTCs.

Despite the relatively indolent nature of most thyroid cancers and the increasing prevalence of low-risk tumors, the early 2000s witnessed striking increases in the use of imaging technology for assessing DTCs. A recent analysis of over 23000 cases of DTC diagnosed in the U.S. confirmed that, although the tumors identified between 2001 and 2009 were more likely to be small $(<1 \mathrm{~cm})$ and localized than in previous years, patients were more rather than less likely to undergo I-131 scintigraphy and cervical US (odds ratios, 1.44 (95\% confidence interval (CI), 1.35-1.54) and 2.15 (95\% CI: 2.02-2.28) respectively) (10). PET studies increased more than 30 -fold between 1996-2004 and 2005-2009, even in patients with localized disease (11).

Efforts are needed to curb this 'diagnostic hyperactivity' and bring post-treatment management strategies more in line with the current challenges of thyroid cancer ( 9 , 12). Aside from the increasing demands for cost-efficient healthcare policies, there is a growing awareness that the increased use of diagnostic imaging does not inevitably translate into increased overall survival. Greater consideration is being given to the potential risks of imaging-related radiation exposure (11) and the impact of excessive surveillance on patients' quality of life (13).

Signs of change are already in the air. Although the major goal of post-treatment surveillance of patients with DTC is still the timely detection and effective management of persistent or recurrent cancer, increasing emphasis is being placed on the need to reliably identify patients who are disease-free and therefore eligible for less-intensive surveillance. Recommendations by national and international bodies are increasingly based on assessments of the individual patient's risk of recurrence (rather than death) (Table 1). Emphasis is also being placed on the dynamic nature of these risks, which evolve over time, spontaneously and in response to treatment (14).

This review will provide a closer look at the evolving evidence-based views on the use and utility of imaging technologies in the post-treatment staging and the short- and long-term surveillance of patients with DTCs. The modalities considered range from whole-body radioiodine scintigraphy and cervical US with Doppler flow analysis - the 'work horses' in both settings - to an expanding palette of increasingly sophisticated crosssectional, functional, combined-modality imaging approaches, which can be used to detect disease that has spread beyond the neck and, in some cases, shed light on its probable outcome.

\section{Cervical ultrasonography}

Cervical US includes gray-scale studies performed with high-resolution linear transducers (frequencies of 10 to $15-17 \mathrm{MHz}$ ) (15) and assessment of lesion vascularity with color or power Doppler. First used in the late 1980s to distinguish cystic from solid thyroid nodules

Table 1 American Thyroid Association criteria for assessing risk of recurrence in patients with DTC.

\begin{tabular}{ll}
\hline Risk & Features \\
Low & $\begin{array}{l}\text { Intrathyroid tumor } \\
\leq 5 \text { lymph node micrometastases }(<0.2 \mathrm{~cm})\end{array}$ \\
Intermediate & $\begin{array}{l}\text { Aggressive histology, minor extrathyroid } \\
\text { extension, vascular invasion }\end{array}$ \\
& $>5$ involved lymph nodes $(0.2-3 \mathrm{~cm})$ \\
High & $\begin{array}{l}\text { Gross extrathyroid extension, incomplete } \\
\text { tumor resection } \\
\text { Lymph node metastases }>3 \mathrm{~cm}\end{array}$ \\
& Distant metastases \\
\hline
\end{tabular}


(15), ultrasound's popularity increased steadily. By the early 2000s, a growing body of evidence indicated that sonographic examination of the neck combined with serum thyroglobulin assays was the most sensitive approach for detecting locoregional DTC involvement $(16,17,18,19)$. In 2006, it was officially recommended for this purpose by the American Thyroid Association (ATA) (20), replacing WBS, which had been the procedure of choice for over 40 years.

Cervical US is inferior to WBS in terms of specificity, and it provides no information on extracervical recurrence, including the upper mediastinum. It is also unsuitable for exploring deep cervical structures (e.g. retro- or parapharyngeal areas) (12). However, highresolution US can pinpoint lesions as small as $2-3 \mathrm{~mm}$ in the thyroid bed or cervical lymph nodes, where the vast amount of persistent/recurrent disease is found in DTC patients. In addition, its diagnostic yield is unaffected by the radioiodine-avidity of the lesions or the presence of anti-Tg antibodies, which can cause false-negative findings in WBS and serum Tg assays (19), and it offers a number of practical advantages, including low cost, wide availability, and no known adverse effects (21).

Its main shortcoming is operator dependency, a problem aggravated by the diverse profiles of the operators examining thyroid cancer patients (e.g. radiology technicians, radiologists, endocrinologists, and other clinical specialists caring for these patients). Efforts have thus been made to define minimum criteria for operators claiming expertise in cervical US and to standardize methods for conducting, interpreting, and documenting the examination results (12). A second important limitation of US is its relatively low specificity, which will be discussed at greater length below.

\section{Normal, suspicious, and indeterminate findings}

Numerous US findings have been analyzed over the years as markers of persistent and recurrent foci of thyroid cancer in the neck. Those considered most useful for this purpose by the European Thyroid Association (ETA) are shown in Figs 1 and 2. Their sensitivities and specificities vary widely, and 'suspicious' lesions are thus distinguished from 'indeterminate' findings, which are atypical but also relatively common in the absence of malignancy.

The low specificity of US findings for distinguishing benign and malignant lesions increases when they are confirmed by cytological analysis of US-guided FNA and/or assay of the needle washout fluid for $\operatorname{Tg}(22,23$, 24); the washout fluid can also be subjected to PCRbased assay of thyroid-specific gene (Tg, TSH receptor) transcripts (25). Current trends, however, are characterized by more cautious use of biopsy (9). Decisions are based on lesion size and/or growth and the likelihood that management will change if positive results emerge. These recommendations reflect a growing awareness of the stress, morbidity, and costs associated with biopsy (26). More importantly, in at least $30 \%$ of cases, reoperation for pathologically confirmed metastases fails to eradicate the disease. It also carries an increased risk of serious, often permanent complications, including nerve resection, hypoparathyroidism, and tracheal or esophageal damage $(27,28)$. Finally, analysis of surgical pathology data on prophylactic neck dissections indicate that up to $90 \%$ of patients with papillary microcarcinomas $(<1 \mathrm{~cm})$ have level VI lymph node metastases, and up to $40 \%$ have lateral compartment involvement $(29,30,31)$. These figures far exceed the clinical locoregional recurrence rates reported for these patients, suggesting that a substantial portion of the cervical disease detected during follow-up is clinically insignificant. FNA should thus be undertaken only after careful consideration of costs, benefits, and the patient's own preferences.

\section{Thyroid bed}

Thyroid bed lesions are a particular concern owing to the proximity of vital structures that can be compressed/ damaged by residual tumor growth (but also by repeat encounters with the surgeon's scalpel, owing to the presence of scar tissue). Postoperative exploration of this area should be postponed until at least 3 months after surgery $(12,32)$. Even then, distinguishing benign and malignant lesions in this area on the basis of US alone is undeniably difficult (Fig. 1). Hypoechogenicity alone may represent autoimmune thyroiditis, suture granulomas, benign reactive lymph nodes, parathyroid adenomas (12), and jugular chain LNs that have slid medially to occupy the bed (33).

Discordant findings have emerged from the few small studies that assessed the diagnostic value of US abnormalities against pathology findings. Lee et al. (34) concluded that benign and malignant lesions could indeed be distinguished on the basis of their margin characteristics, shapes, and calcification statuses. Margin irregularity (Fig. 2E) - a feature whose detection is associated with particularly high interoperator 
Normal

- Triangular or flattened area that is uniformly

hyperechoic vs

surrounding muscle tissue (A)

- Ovoid lesions, that is uniformly hyperechoic or isoechoic vs surrounding muscle tissue (B)

Indeterminate

- Lesions displaying hypoechogenicity alone (C, D)

\section{Suspicious}

- Taller-than-wide in transverse plane $(\boldsymbol{E})$

- Irregular margins (E)

- Microcalcifications (F)

- Cystic changes (G)

- Increased vascularization
A

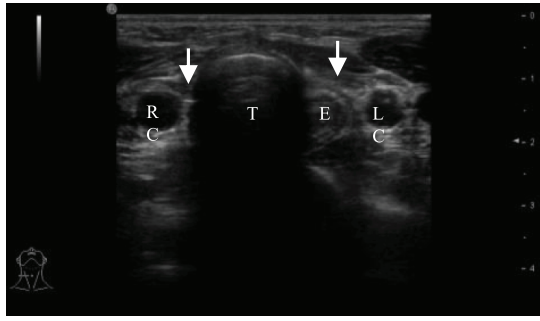

C

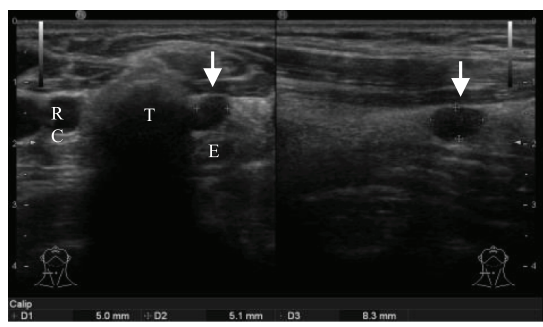

E

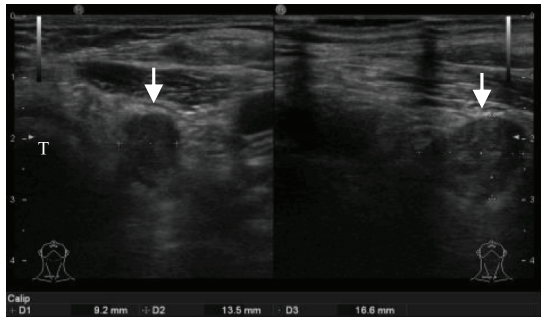

G

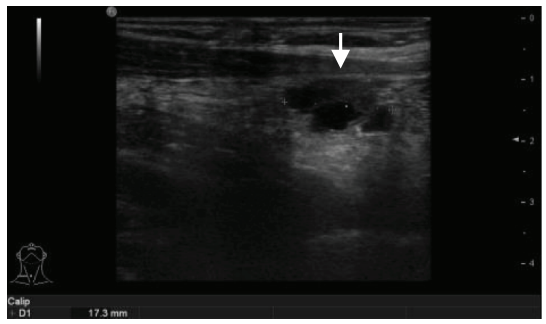

D

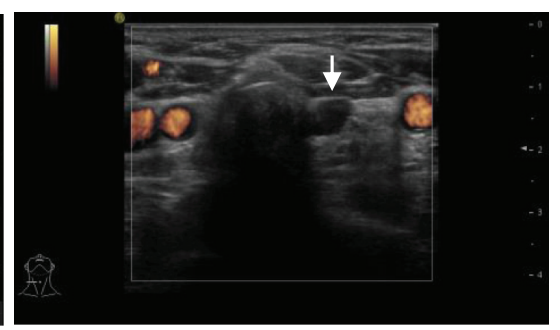

$\mathrm{F}$

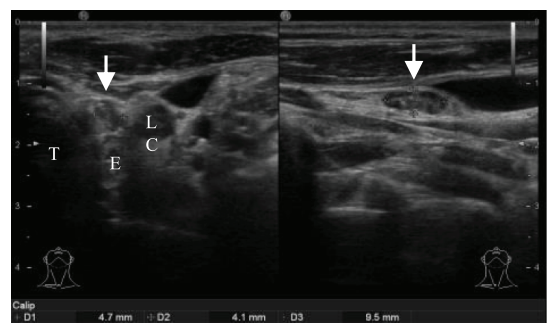

B

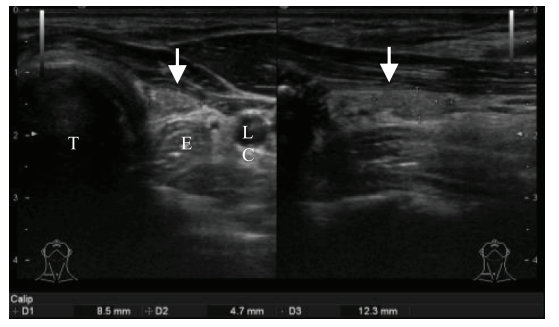

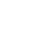




\section{US findings}

Normal

- Identifiable (hyperechoic) hilum (A)

- Ovoid shape (A)

- Normal size (short axis diameter $\leq 8 \mathrm{~mm}$ for level $\mathrm{II}$, $\leq 5 \mathrm{~mm}$ for levels III, IV and VI) (A)

- Absent or exclusively hilar vascularization (B)

\section{Indeterminate}

Absence of hilum +1 or more of the following:

- Round shape (C)

- Increased size (short axis diameter $\geq 8 \mathrm{~mm}$ for level $\mathrm{II}$, $\geq 5 \mathrm{~mm}$ for levels III, IV and VI) (C)

- Increased central vascularization

\section{Suspicious}

- Hyperechoic thyroid-like tissue (D)

- Microcalcifications (D)

- Cystic changes (E)

- Peripheral vascularization (F)

\section{Images}

A

B
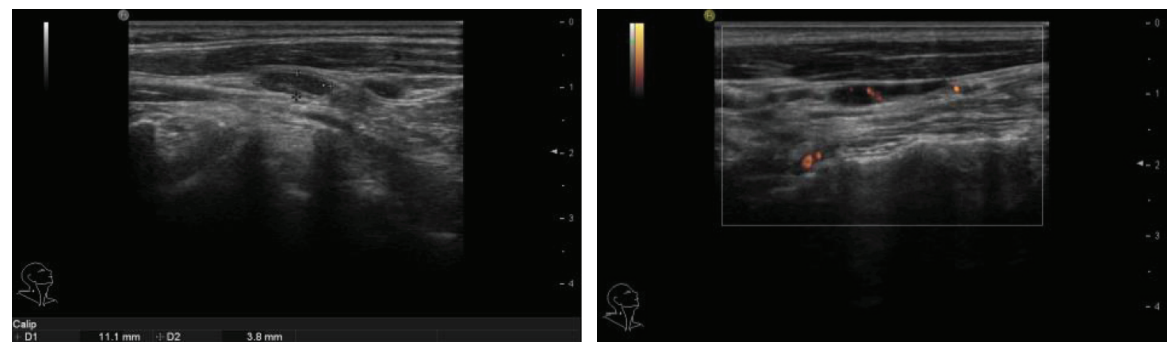

C

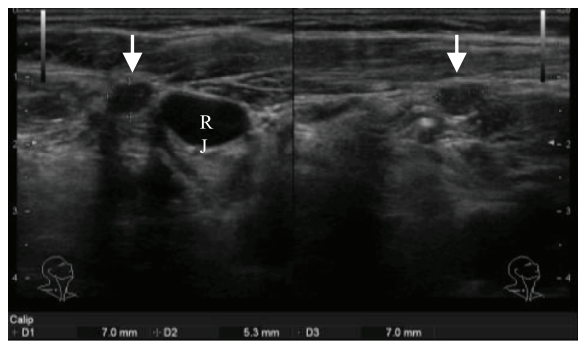

$\mathrm{D}$

E
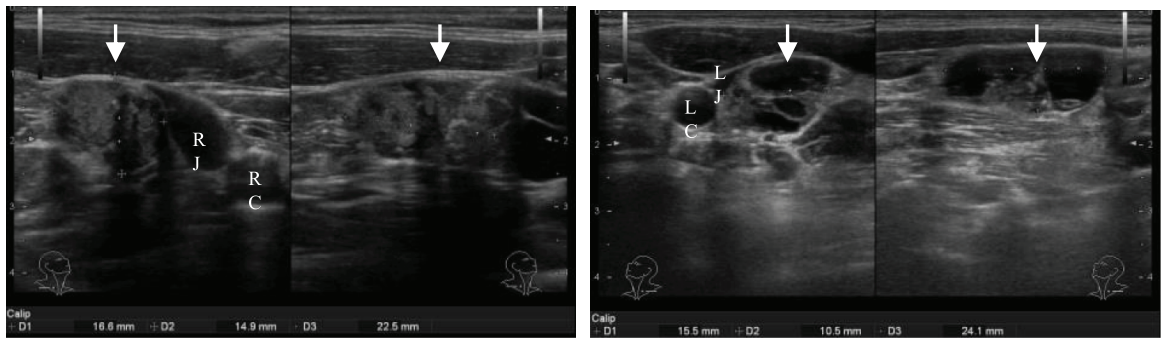

$\mathrm{F}$

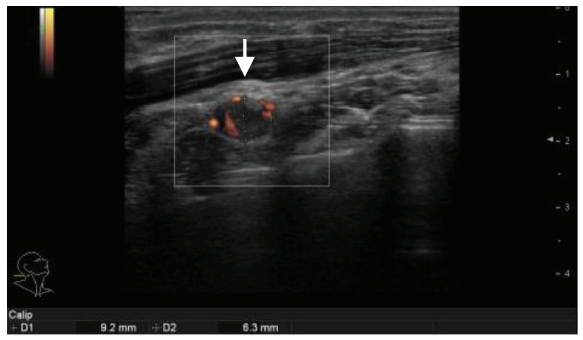

\section{Figure 2}

Classification of post-treatment sonographic findings of cervical lymph nodes. Panels A and B. Normal findings: This right cervical lymph node (arrows) has a hyperechoic hilum, an elongated shape, short axis $\leq 5 \mathrm{~mm}$, and exclusively hilar vascularization. Panel C. Indeterminate findings: Right cervical lymph node (arrows) with loss of hilum, round shape, and short axis $\geq 5 \mathrm{~mm}$. Panels $\mathrm{D}, \mathrm{E}$ and F. Suspicious findings: (D) Right cervical lymph node (arrows): thyroid-tissue-like appearance and microcalcifications with posterior shadowing; (E) suspicious left cervical lymph node (arrows) with cystic areas with posterior acoustic enhancement; (F) round right cervical lymph node (arrows) displaying peripheral vascularization. LC, left carotid artery; LJ, left jugular vein; RC, right carotid artery; RJ, right jugular vein; US, ultrasound. 

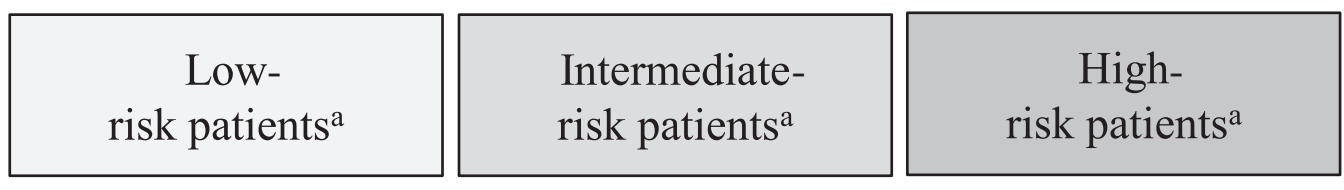

\section{First-line imaging studies}

- Neck US

- Neck US

- Consider DxWBS / SPECT-CT
- Neck US

- Consider DxWBS /

SPECT-CT ${ }^{b}$

- Consider CT/MRI

\section{In the presence of any of the} following...

- Structural evidence of disease on neck US and/or

- Non-stimulated Tg $>5-10 \mathrm{ng} / \mathrm{mL}$

- Rising Tg levels

- Rising Tg antibodies

- Symptoms referable to distant metastases
- Non-stimulated Tg $>10 \mathrm{nd} / \mathrm{mL}$ and negative radioiodine imaging

or

- As a prognostic/predictive tool in patients with metastatic disease ${ }^{c}$

\section{...consider performing:}

\section{Second-line imaging studies}

- DxWBS / SPECT-CT

- ${ }^{18} \mathrm{FDG} / \mathrm{PET}$ scan and/or

- Chest CT without i.v. contrast (pulmonary parenchyma) and with i.v. contrast (mediastinum) and, if negative:

- CT/MRI of the abdomen and/or MRI brain/skeleton and/or

- ${ }^{18} \mathrm{FDG} / \mathrm{PET}$ scan 
variability (35) - emerged as the most sensitive (79\%) and specific $(100 \%)$ predictor of thyroid bed recurrence. This feature, however, was found in only $10 \%$ of the confirmed recurrences reported by Shin et al. and $6 \%$ of those classified as 'non-recurrences'. In fact, they found no significant differences between these two classes of lesions in terms of size, shape, echogenicity, margins, calcification, or vascularity and concluded that they could not be reliably differentiated without biopsy (36).

The ETA currently recommends FNA for sonographically suspicious thyroid bed lesions that measure $10 \mathrm{~mm}$ or more or display active growth (12). For smaller nodules $(<11 \mathrm{~mm})$, growth is actually rare ( $<10 \%$ of cases), particularly when they exhibit no suspicious features (Figs 1 and 2 ) and are not accompanied by cervical lymphadenopathy or detectable/increasing Tg production. The growth that does occur is typically quite slow (roughly $1 \mathrm{~mm} /$ year), suggesting that small thyroid bed nodules can be safely managed with cautious observation and serial sonographic examinations of the neck (37).

\section{Cervical lymph nodes}

Metastatic involvement is more commonly found in level III, IV, and VI nodes than in those of level II $(38,39)$. Normal nodes are typically oval, with short to long axis ratios of $<0.5$ (Fig. 2A) (15). Size provides limited information on the likelihood of malignancy. Normal ranges vary with the location, with larger nodes found in the submandibular region (level II), possibly because of reactive phenomena related to chronic oral cavity inflammation. Furthermore, many metastatic nodes are normal in size (40).

Studies correlating preoperative sonographic and surgical histology findings indicate that a nonvisualized hilus is the most sensitive predictor of lymph node malignancy (100\%), but its specificity was dismally low (29\%). The most specific findings are cystic changes (100\%), punctuate hyperechogenicity (representing colloid or microcalcifications) (100\%), and peripheral vascularization
(82\%), which also display relatively high sensitivity (86\%) (38). In light of these findings, a productive strategy for pinpointing worrisome lymph nodes might begin with a thorough Doppler-based assessment of vascularity in all nodes lacking a hilus (15).

The ATA reserves FNA for sonographically suspicious lymph nodes that exceed $8-10 \mathrm{~mm}$ (smallest diameter) and/or display active growth (9). Nodes with suspicious and especially indeterminate findings do not generally increase in size. In a retrospective study on the natural course of US-detected lymph node abnormalities in 166 patients followed with serial US, only $20 \%$ of the abnormal nodes lesions grew $\geq 3 \mathrm{~mm}$ during the first 3 years after surgery; moreover, none caused pain or compression of vital structures, and 14\% disappeared entirely over time, with no treatment at all (41).

\section{Post-treatment staging and surveillance}

Ultrasound plays an especially important role in the early surveillance of the growing subpopulation of DTC patients treated with lobectomy or with total/near total thyroidectomy without RRA $(12,42,43)$. In the presence of normal thyroid tissue (even small remnants), the result of a single serum Tg assay is of limited use. In these cases, Tg assays provide reliable information on the presence of persistent/ recurrent disease only later, when serial measurements are available, and can be analyzed to identify increases in $\mathrm{Tg}$ production over time $(44,45,46,47)$. Substantial rises are an indication for additional imaging work-up (US and/or second-line studies) (Fig. 3) $(9,12)$.

Normal findings in the initial post-treatment neck scan are strongly associated with excellent long-term outcomes (14). The negative predictive power is virtually $100 \%$ in very low-risk patients with microPTCs (48) and excellent in intermediate-risk patients as well. Peiling Yang et al. reviewed 90 cases of ATA intermediate-risk PTC treated with total thyroidectomy and RRA, with negative basal $\mathrm{Tg}$ and $\mathrm{TgAb}$ assays, and negative or only indeterminate findings (Figs 1 and 2) on the first post-treatment US.

\section{Figure 3}

Risk-stratified use of diagnostic imaging modalities in the initial post-therapeutic staging of differentiated thyroid cancer. (a) Risk of persistent/recurrent disease as reported in the 2015 American Thyroid Association Guidelines for the Management of Thyroid Nodules and Differentiated Thyroid Cancer (Haugen 2015). (b) In patients with uptake on DxWBS, SPECT-CT allows (i) more precise anatomical localization of radioiodine uptake, (ii) exclusion of nonspecific uptake, and (iii) identification of noniodineavid lesions. (c) ${ }^{18} \mathrm{FDG} / \mathrm{PET}$ helps identify patients at highest risk for rapid disease progression and disease-specific mortality (prognostic role) and/or those with radioiodine-refractory disease (predictive role). ${ }^{18} \mathrm{FDG} / \mathrm{PET}$, ${ }^{18} \mathrm{~F}$-fluorodeoxyglucose positron emission tomography; CT, computed tomography; DxWBS, diagnostic whole-body scan; MRI, magnetic resonance imaging; SPECT, single-photon emission computed tomography; Tg, thyroglobulin; US, ultrasound. 
The rate of structural disease recurrence during follow-up (median 10years) was $8 \%(4 / 49)$ in the subgroup whose initial US findings were negative (as opposed to $12 \%$ $(5 / 41)$ in the group with indeterminate scan results) (49).

In many facilities, neck sonography is still done routinely, once or even twice a year, even when the risk of recurrence is low $(12,50)$. A recent retrospective analysis of over 1000 cases of PTC treated between 2000 and 2010 at Memorial Sloan Kettering Cancer Center found that during the first 3 years of surveillance, the number of US examinations per patient ranged from 1.3 in low-risk patients to 1.9 and 1.8 in intermediate- and high-risk groups - already appreciably lower than rates reported in other retrospective studies (51). Nonetheless, the number of scans needed to detect 1 recurrence event in the low-risk cohort (154.0) was 6-7 times higher than those of the intermediate and high-risk groups (23.9 and 13.0 respectively), indicating that there is substantial room for improving the cost-effectiveness of US surveillance of low-risk patients (50).

Similar conclusions were reached in the study cited above by Peiling Yang et al. (49). The 90 intermediate-risk patients they retrospectively reviewed were followed with routine cervical US and Tg assays at 6-12 month intervals, and structural recurrence emerged in only 9 (10\%). All the lesions were sonographically detected. However, in $5 / 9$ cases, the disease was also heralded by other findings (rising Tg levels in most cases) and would thus have been identified even if US had not been used so frequently. These authors also underscored the high probability of false-positive findings associated with frequent US examinations in populations of this sort. In 51 (57\%) of the cohort patients, the routine scans yielded new or persistently atypical findings, which led to a host of additional diagnostic procedures (first- and second-line imaging procedures, FNA), none of which disclosed any clinically significant structural disease. On the basis of these findings, these authors suggest that in intermediate-risk DTC patients whose initial post-treatment assessment reveals no structural or biochemical evidence of disease, sonographic surveillance can be discontinued if the second assessment is also negative (49).

These conclusions are supported by recent findings confirming the strong associated between normal findings at the initial assessment and excellent long-term outcomes (14). They are also consistent with the ETA's current guidelines regarding the first 5 years of follow-up, when over three-quarters of recurrences are identified (3). During this period, yearly US scans are recommended only for patients meeting the ETA's high-risk criteria (some of whom are classified as intermediate-risk according to ATA criteria) and only when warranted by pTNM staging, serum Tg levels, and responses to therapy (12). For lowand very low-risk patients with normal findings at 6 months, 'regular' scans are considered unnecessary.

When doubts on the presence of distant metastases arise, additional imaging is required (Fig. 3). The following section provides a concise profile of the methods most commonly used.

\section{Cross-sectional imaging}

The cross-sectional imaging studies include CT and MRI scans. Both allow high-precision anatomic localization and measurement of disease foci and are especially useful for assessing the tumor burden in patients with extensive local disease or distant metastases. To identify the nature of the mass, however, the results have to be interpreted within the clinical context of the individual patient. When doubts arise or discordant findings emerge (e.g. a lesion compatible with metastatic lung disease in a low-risk patient with undetectable serum $\mathrm{Tg}$ and negative Tg antibody assays), cytological or histological confirmation is needed. When foci of metastatic disease are found, options include local or systemic therapy and simple surveillance alone. Lesions that represent no immediate threat to the patient should be treated only if the tumor burden is substantial or when there is obvious progression. The latter can be documented using the Response Evaluation Criteria in Solid Tumors, RECIST 1.1 system) (52).

Evidence supporting the utility of cross-sectional imaging modalities comes largely from experience with other solid tumors; data on their specific use in thyroid cancer are lacking. According to the ATA, cross-sectional imaging of the neck and chest should be considered in the following cases: (i) patients with extensive recurrent nodal disease; (ii) patients with negative findings on cervical US and WBS and a high serum Tg level (generally exceeding $10 \mathrm{ng} / \mathrm{mL}$ ), or rising Tg or Tg antibodies values; and (iii) in cases where reliable assessment of potential aerodigestive tract invasion is needed (9). Rarer sites of thyroid cancer metastases should be explored when a clinical suspicion arises or in high-risk patients with high serum thyroglobulin levels $(10 \mathrm{ng} / \mathrm{mL})$ and no evidence of lung/mediastinal metastases (Fig. 3).

The optimal timing for cross-sectional imaging studies in patients with DTC is not well defined: recommendations range from 3 to 12 months after treatment, depending on the tumor burden, location of the disease, 
histology, and Tg trend (9). Anyway, many thyroid cancer clinical trials have enrolled patients with progressive disease evaluated over a period of $\leq 12$ months and baseline assessment performed no more than 4 weeks before treatment introduction (52).

\section{Computed tomography}

The anatomic resolution of a CT scan is sufficiently high to allow precise localization of disease foci, and compared with other second-line studies, it offers distinct advantages in terms of availability, cost, and examination times. The lungs can be explored with high-resolution CT without contrast (9), but contrast-enhancement with iodine is best for exploration of the mediastinum. Contrast-enhanced scans are also recommended before surgery to identify possible areas of vascular invasion; for assessment of the retrotracheal space, it is used as a complement to neck US (9).

The radiation exposure associated with CT imaging has been linked to an increased risk of cancer (53). This risk should be weighed against the aggressiveness of the patient's disease when decisions are being made on the use and frequency of CT in the post-treatment surveillance of DTC patients.

\section{Magnetic resonance imaging}

Unlike CT, MRI is associated with absolutely no radiation exposure. It offers excellent soft-tissue contrast, which is particularly useful when esophageal and/or tracheal invasion is suspected $(54,55)$. Although its specificity is relatively low (51\%), MRI offers excellent sensitivity (95\%) for the detection of metastatic lymphadenopathy in DTC patients (56). It is particularly useful for ruling out nodal involvement in the mediastinum (57), which is poorly visualized on ultrasound. Its main shortcomings are related to the duration of the examination and the possibility of false-negative findings related to movement artifacts.

MRI is the imaging modality of choice for identifying thyroid cancer metastases to the bone, brain, or liver. The bones most frequently targeted by these lesions (and metastases from other cancers as well) are those with high blood flow: the vertebrae, the ribs, and the hips (58). Its high soft-tissue contrast is very useful for exploring the marrow and paraosseous structures (e.g. spinal canal) with a detection limit of $2 \mathrm{~mm}$ (59). Wholebody MRI has displayed $100 \%$ sensitivity, $80 \%$ specificity of $80 \%$, and $96 \%$ accuracy in the detection of bone metastases in cancer patients, and its performance is only slightly inferior in patients harboring more than one lesion (sensitivity, specificity, and accuracy: 94, 76, and 91\% respectively (59). The addition of background body signal suppression (DWIBS) significantly increases the accuracy of MRI for bone metastasis detection, and the accuracy of this approach has proved to be similar to that of ${ }^{18} \mathrm{~F}$-fluorodeoxyglucose PET (94\%) in a small cohort of 23 patients (60).

In patients with solid tumors, MRI is superior to CT for the detection of brain metastases because it provides higher soft-tissue contrast, no bone artifacts, and fewer partial volume effects. Paramagnetic contrast agents also produce significantly stronger enhancement than those used with CT (61). In the presence of multiple brain lesions, roughly $20 \%$ of the lesions identified with MRI are missed on CT (61).

Approximately, $0.5 \%$ of DTC metastases are located in the liver. They usually develop late in the course of the disease in patients with other distant metastases (62). Evidence-based guidelines recommend CT or MRI identification of liver metastases. Data are lacking in DTC, but MRI is considered preferable to $\mathrm{CT}$ for exploring liver metastases from most endocrine tumors $(63,64)$.

\section{Functional imaging}

\section{Radioiodine imaging}

Radioiodine imaging exploits the capacity of thyroid cells to take up iodine from the circulation, which is mediated by the sodium iodine symporter (NIS). This capacity is generally preserved in thyroid cancer cells although they might display decreased $(65,66)$ or even absent $(67,68)$ NIS expression. Iodine metabolism in thyroid cancer cells can also be influenced by somatic mutations, such as BRAF V600E, which is associated with downregulated expression of iodide-metabolizing genes (69). Radioiodine can be used to obtain planar or three-dimensional images (classic radioiodine scintigraphy vs single-photon emission computed tomography, SPECT).

\section{Diagnostic whole-body radioiodine scintigraphy}

Although the accuracy of a diagnostic WBS is approximately $84-90 \%$, its specificity $(91-100 \%)$ far exceeds its sensitivity $(27-55 \%)(70,71,72,73)$. It is the most sensitive tool for thyroid remnant detection and thyroid remnant ablation assessment $(74,75)$. It is also useful for early detection of distant metastases. These lesions, however, are relatively uncommon in DTC 
patients: they are found in only $\sim 3 \%$ of DTC patients at diagnosis and in $10 \%$ or less during follow-up $(3,76,77)$. The ATA thus recommends routine diagnostic WBS during follow-up only when the risk of persistent/recurrent disease and extracervical metastases is intermediate or high (Fig. 3) (9). Even in these cases, there is no need to repeat the DxWBS if the RxWBS yields negative findings, especially if $\mathrm{Tg}$ production is undetectable and the $\mathrm{Tg}$ antibody assay is negative $(17,78,79,80,81)$. In contrast, DxWBS can be useful for monitoring (and for planning additional imaging work-up) of distant and/or local foci of radioiodine uptake revealed on post-therapeutic WBSs, and it is also an option for assessing the presence of distant metastases when positive Tg antibody levels render serum Tg levels unreliable markers of disease (9).

DxWBS can also be helpful in calculating therapeutic doses of radioiodine (82). It is important to recall, however, that a diagnostic dose of ${ }^{131}$ I (the isotope most widely used for diagnostic scans in DTC patients) can reportedly reduce the uptake of radioiodine subsequently administered for therapeutic purposes, particularly when the two administrations are separated by more than 3 days and fewer than 7 days - a phenomenon known as the 'stunning effect' (83). However, in a recent study of two consecutive cohorts of DTC patients undergoing RRA, ablation rates and detection rates of disease recurrence were similar in the patients whose ablations were or were not preceded by a diagnostic scan (84). Stunning is not caused by diagnostic scans performed with ${ }^{123} \mathrm{I}(85,86$, 87). This pure gamma emitter is ideal for use with modern gamma cameras and provides higher image resolution than ${ }^{131}$ I. Its use is limited, however, by its high cost and low availability (due to its short half-life).

WBS has a number of practical drawbacks. The detection limit depends on several factors, including the activity administered, the timing of image acquisition following RAI administration, the type of equipment used (crystal thickness), and the patient's renal function status (88). A successful scan also requires a lengthy period of patient preparation (3-4 weeks) to maximize tracer uptake. This involves a low iodine diet and elevation of TSH levels by withdrawal of thyroid hormone replacement therapy. The latter is often associated with unpleasant symptoms of hypothyroidism. Administration of recombinant human TSH (rhTSH) is an effective alternative that is more expensive but decidedly better tolerated. In addition, patients who have recently undergone computed tomography scanning with iodinated contrast medium must wait $4-8$ weeks before they have a radioiodine WBS (89). Radiation exposure is also a consideration. The examination involves administration of a radioactive tracer (albeit at low doses). The radiation risk also involves persons who are in contact with the patients, so radioprotection measures must be adopted for the 10-15 days following the scan. Disease is anatomically located based on the RAI uptake observed on the planar whole-body image and, if necessary, images of specific body regions, such as the neck. The precision of this approach is nonetheless limited. Because RAI can be concentrated by both normal and neoplastic thyroid tissue, RAI scintigraphy cannot be used to identify foci of persistent/recurrent disease in the thyroid bed. False-positive results can also be caused by the physiologic or pathologic accumulation of radioiodine in nonthyroidal tissues and body fluids (Table 2) (90). The sensitivity of WBS can be reduced in the presence of large amounts of normal thyroid tissue: these remnants can sequester almost all of the administered ${ }^{131}$ I activity, thereby reducing visualization of smaller metastatic lesions (9). When a large remnant is visualized on post-therapeutic WBS, a diagnostic WBS can be evaluated to reassess the presence of local or distant metastases (9). WBS is also of no value in the patients whose tumors have lost the ability to concentrate RAI (91), a phenomenon encountered in up to two-thirds of patients with distant metastases (the subpopulation most likely to benefit from WBS) (92).

\section{Single-photon emission computed tomography/ computed tomography}

In single-photon emission computed tomography (SPECT), the two-dimensional tomographic images acquired with the SPECT gamma camera are elaborated to provide a threedimensional representation of the region being examined. SPECT-CT involves the co-registration and fusion of SPECT images and those acquired with a conventional CT scan. This dual-modality approach improves the localization

Table 2 False-positive radioiodine uptake.

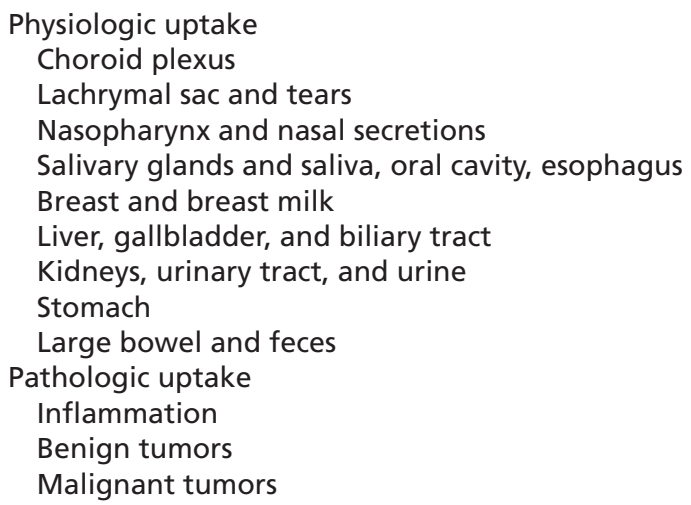


and facilitates measurement of lesions seen on SPECT scintigraphy. The specificity of SPECT-CT is high (up to $100 \%)$ and the sensitivity is $50 \%(93)$.

Costs and availability are major considerations in decisions on the use of SPECT-CT. In the follow-up of patients with DTC, SPECT-CT is performed with diagnostic or therapeutic activities of radioiodine. Consequently, it has the same drawbacks as RAI WBS in terms of patient preparation and the need for postscan radioprotection measures. On the other hand, the SPECT-CT fusion images elaborated by the scanner software allow more precise localization of foci of RAI uptake as well as lesions that are not RAI-avid. For this reason, SPECT-CT is less likely to produce false-positive and indeterminate results $(94,95)$, and it reportedly provides a gain in information over that furnished by WBS alone in 35-68\% of patients $(94,96,97)$. In a recent study, SPECT-CT performed after RRA revealed additional disease foci (neck lymph nodes and/or distant metastases) in about $9 \%$ of the patients whose RxWBS showed uptake only in the thyroid bed. Results of this type were particularly common when stimulated Tg levels were $\geq 1.8 \mathrm{ng} / \mathrm{mL}$. In patients with RxWBS findings suggestive of cervical lymph node metastasis, $40 \%$ of the lesions were reclassified as normal thyroid remnants on the basis of SPECT-CT results (98).

\section{${ }^{18} \mathrm{~F}$-fluorodeoxyglucose positron emission tomography}

Positron emission tomography is being employed more and more often for all types of cancers. The most common tracer used in clinical settings is ${ }^{18} \mathrm{FDG}$, a glucose analog that is taken up by benign as well as neoplastic cells. The latter cells' demand for glucose, however, is markedly increased owing to their reliance on anaerobic glycolysis, which is far less efficient for energy production than oxidative phosphorylation. The metabolic information provided by this technique is the basis for PET's use as a diagnostic and prognostic tool in cancer patients (e.g. for evaluating the response to treatment and estimating the risk of death). The PET/CT is a more recently developed technique that uses integrated scanners to acquire PET and CT images in a single session. The combination of functional and morphologic data furnished by this approach substantially improves the anatomic localization of lesions. Two meta-analyses analyzed the diagnostic performances of ${ }^{18} \mathrm{FDG}$ PET and ${ }^{18} \mathrm{FDG}$ PET/CT for the detection of persistent/recurrent DTC in patients with detectable $\mathrm{Tg}$ and no evidence of RAI uptake $(99,100)$. In both cases, the patient-based sensitivity of PET/CT was appreciably higher than PET alone (93-94\% vs $83-84 \%$ for ${ }^{18}$ FDG PET). The ATA strongly recommends ${ }^{18}$ FDG PET/CT for high-risk DTC patients with elevated basal or stimulated serum Tg (generally $>10 \mathrm{ng} / \mathrm{mL}$ ) and negative findings on radioiodine imaging during follow-up (9). In case of lower thyroglobulin levels, ${ }^{18}$ FDG PET/CT can be false negative due to the presence of microscopic disease. The specificities of ${ }^{18} \mathrm{FDG}$ PET alone and PET/CT methods were similar $(81-84 \%)(99,100)$. This is due to the fact that inflammation also increases FDG uptake. When ${ }^{18}$ FDG PET is used to stage DTC, care must be taken to differentiate increased uptake by thyroid-derived neoplastic tissue from that observed in nonthyroid tumors (Fig. 4). Uptake can also be increased merely by the presence of inflammation (e.g. reactive lymph nodes, inflammatory joint changes) (Fig. 4).

\section{Disease relapse and staging}

${ }^{18}$ FDG PET findings lead to changes in patient management strategies (generally involving the surgical plan) in about $30 \%$ of the cases $(101,102,103)$. As noted, however, false positivity related to inflammation is possible. Therefore, if surgery is planned on the basis of FDG uptake, the true metastatic nature of cervical lymph nodes must always be verified intraoperatively or preoperatively via FNA.

${ }^{18}$ FDG PET positivity in thyroid cancer is influenced by several other factors, including primary tumor histology, the presence of RAI-refractory disease, overall tumor burden, disease localization, and TSH levels at the time of the scan. ${ }^{18}$ FDG avidity is most commonly seen in the more aggressive DTC forms. Histopathological analysis of distant metastases from $70{ }^{18}$ FDG-avid thyroid tumors revealed that almost half were poorly differentiated cancers, 20\% were tall-cell variants, and 9\% were Hürthle cell carcinomas. However, almost one-fourth (23\%) were welldifferentiated cancers. In 16 (37\%) of the 43 patients whose primary tumor was also analyzed, the ${ }^{18} \mathrm{FDG}$-avid metastases presented more aggressive histological features than the primaries (104). Distant metastases that take up ${ }^{18} \mathrm{FDG}$ are frequently refractory to radioactive iodine therapy, even at high doses, and most of these lesions exhibit signs of metabolic progression during the first year after treatment (105). ${ }^{18}$ FDG uptake in RAI-refractory thyroid cancer is correlated with loss or downregulation of NIS expression and increased expression of glucose transporter 1 . The $B R A F$ V600E mutation can also cause this metabolic pattern, and this may explain the ${ }^{18}$ FDG uptake observed in welldifferentiated thyroid cancer harboring this mutation (69). Patients with detectable thyroglobulin production and suspected recurrence are sometimes referred for empirical RAI treatment to search and treat disease localization. However, 

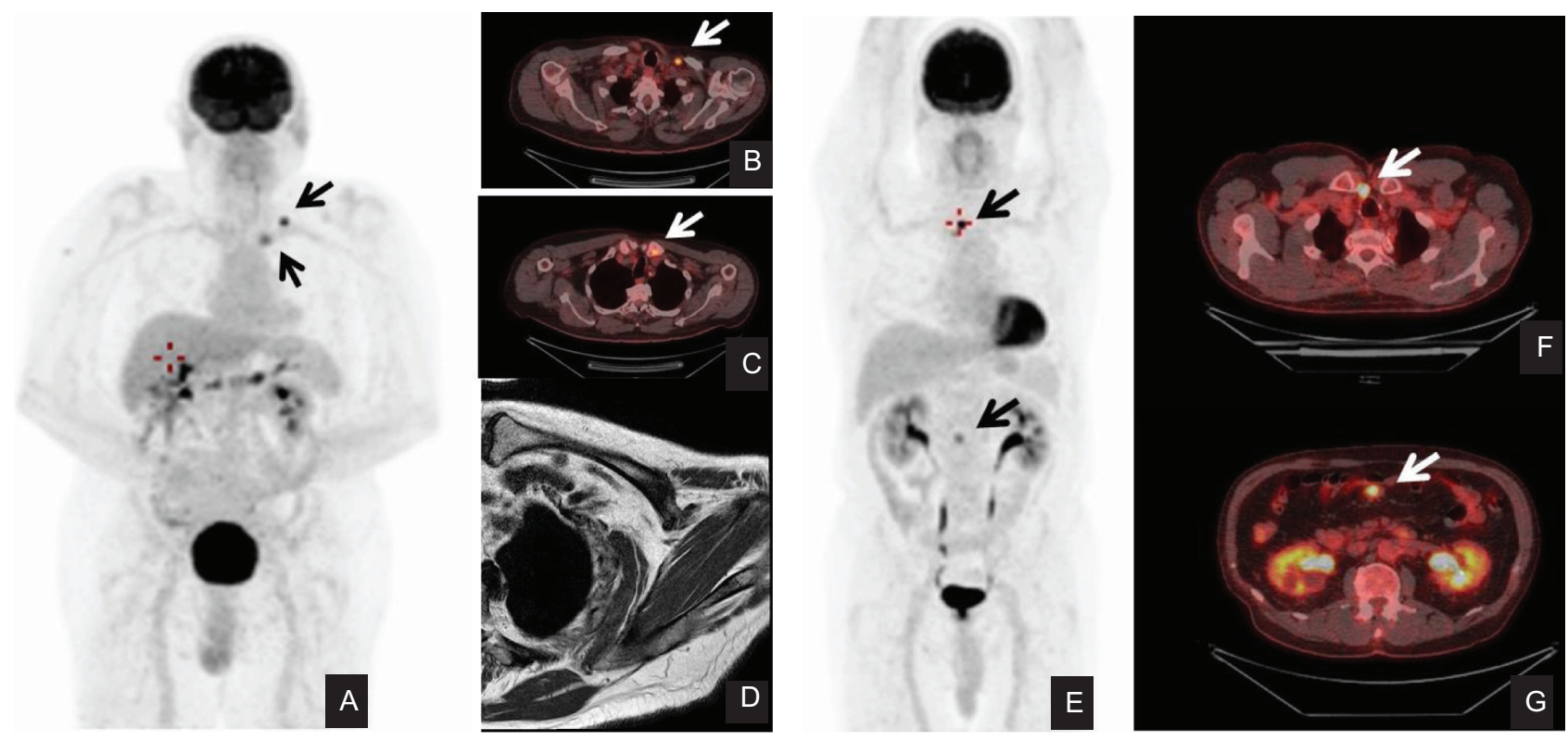

\section{Figure 4}

${ }^{18}$ FDG PET findings in the follow-up of differentiated thyroid cancer. ${ }^{18} \mathrm{FDG}$ PET/CT in a patient with tall-cell variant thyroid cancer (panel A) showed a retroclavicular left metastatic lymph node (panel B, axial view) and high and focal uptake also in the left clavicle (panel C, axial view) suspicious of bone metastases. MRI confirmed to be arthrosis (panel D). FDG PET in a patient with recurrent papillary thyroid cancer (panel E). High FDG uptake was detected in a superior mediastinal lymph node (panel F, axial view) and in mesenteric lymph node (panel G, axial view) suspicious for recurrence. Biopsy confirmed thyroid cancer recurrence in the mediastinal lymph node, but it was in favor of a B cells lymphoma in the mesenteric lymph node.

in roughly one-third of these patients, the post-treatment whole-body RAI scan is negative and ${ }^{18}$ FDG PET is more sensitive to detect recurrence, suggesting that it might be useful to perform ${ }^{18}$ FDG PET before giving empiric radioactive iodine treatment in these patients (106).

In addition to its recommended role in the follow-up of patients with aggressive histology and RAI-refractory disease, FDG PET is also potentially useful in the primary staging of high-risk patients (Table 1). Lee et al. retrospectively analyzed 258 patients who underwent RRA and ${ }^{18}$ FDG PET/CT during the same period of time. Compared with the post-treatment WBS, ${ }^{18} \mathrm{FDG}$ PET/CT revealed additional positive findings in $25 \%$ of the patients with highor intermediate-risk thyroid cancers (pT3-T4N1 and tumor size $>2 \mathrm{~cm}$ ) but only 3-6\% of those with lower-risk tumors (T3-T4 N0 or T1-T2 N1 and size $<2 \mathrm{~cm}$ ), and the gain in information led to a change in management in $17 \%$ of the cases (107). Nascimento et al. retrospectively evaluated 38 patients with aggressive thyroid cancer histotypes and no evidence of disease after surgery. ${ }^{18}$ FDG PET/CT performed after the first RRA revealed persistent disease in 15 (39\%) of these patients; only 12 of these cases were identified with the post-therapeutic RAI WBS (108). Of the 86 lesions detected in this cohort, $41 \%$ were detected only by ${ }^{18} \mathrm{FDG}$ PET/CT and 31\% were seen only on the post-therapeutic WBS, indicating the two techniques play complementary roles (108). Additional studies are nonetheless necessary to validate the utility of this approach in routine practice.

The serum thyroglobulin level is an indirect index of the tumor burden. Current guidelines recommend ${ }^{18} \mathrm{FDG}$ PET/CT when Tg levels exceed $10 \mathrm{ng} / \mathrm{mL}$ (9), and this threshold has been used in several studies. However, FDG PET positivity is also associated with lower thyroglobulin levels $(101,109)$. For this reason, lower thresholds have been proposed. Giovanella et al., for example, suggested a level of $4.6 \mathrm{ng} / \mathrm{mL}$, which was associated with a sensitivity of $96 \%$ (110). Based on a subsequent analysis of 102 cases, the same investigators also demonstrated that ${ }^{18} \mathrm{FDG}$-PET positivity is predicted by a serum thyroglobulin doubling time of less than 1 year, regardless of the Tg level itself (111).

Ultrasonography is still the best tool for detection of cervical lymph node metastases, but ${ }^{18}$ FDG PET can be useful for identifying recurrence in areas that are difficult or impossible to explore sonographically, such as the upper mediastinum or the retropharyngeal region $(101,112)$. As for distant metastases, ${ }^{18}$ FDG PET can often 
detect small bone lesions that are missed on CT or MRI scans. However, CT is still the method of choice for identifying lung metastasis, especially the micronodular form that is so common in thyroid cancer. These lesions are often ${ }^{18}$ FDG-negative due to a partial volume effect (113).

The sensitivity of ${ }^{18}$ FDG PET can be influenced by TSH stimulation. Conflicting results have been reported on this issue. However, in a recent meta-analysis of seven prospective controlled clinical trials (168 patients), per-patient and per-lesion analyses both revealed more positive findings and a better tumor/background ratio when ${ }^{18} \mathrm{FDG}$ PET was performed under TSH stimulation than when it was done during LT4 treatment (114). However, ${ }^{18}$ FDG PET performed after the administration of rhTSH has also been associated with false-positive findings, especially in cervical lymph nodes. As noted above, positive ${ }^{18} \mathrm{FDG}$ findings must be interpreted with caution (102). If, for practical reasons, ${ }^{18}$ FDG PET cannot be performed under TSH stimulation during follow-up, it can be done at the time of RAI treatment to take advantage of the TSH stimulation.

\section{Prognostic value}

In DTC patients with distant metastases, reported 10-year survival rates range from 25 to $42 \%$, and the presence of RAI-refractory disease is a major determinant of mortality (92). ${ }^{18}$ FDG uptake is currently considered an important tool for predicting overall survival and response to therapy in this population. In a study of 80 patients with distant metastases from thyroid cancer, ${ }^{18} \mathrm{FDG}$ uptake was the only independent predictor of overall survival: rates at 2 years were $100 \%$ in patients with ${ }^{18}$ FDG-negative lesions but only $60 \%$ for those who were ${ }^{18}$ FDG-positive. Furthermore, in the PET-positive subgroup, overall survival was unrelated to the lesions' RAI avidity. Mortality was also associated with the ${ }^{18} \mathrm{FDG}$ uptake level (SUV Max of $>5$ ) and number of ${ }^{18}$ FDG-avid lesions (>10) (115), which is consistent with previous findings (116). Wang et al. found no significant response to radioactive iodine therapy in lesions that displayed ${ }^{18} \mathrm{FDG}$ uptake, even those that also took up radioactive iodine (105). ${ }^{18} \mathrm{FDG}$ uptake is also correlated with other clinical factors that predict nonsurvival and/or nonresponse to ${ }^{131}$ I treatment, such as age over 45 years and the presence of necrosis $(115,116)$.

\section{Other radiopharmaceuticals}

PET can also be performed with iodine-124 ( $\left.{ }^{124} \mathrm{I}\right)$. The sensitivity of this approach exceeds that of diagnostic and therapeutic WBS done with ${ }^{131}$ I not only because it provides tomographic images, but ${ }^{124} \mathrm{I}$ PET also offers higher resolution $(117,118,119)$. Nonetheless, it has also been associated with false-negative findings in patients with miliary lung nodules (120). The half-life of ${ }^{124} \mathrm{I}$ (4.2 days) allows the acquisition of sequential images for uptake quantification over time. ${ }^{124}$ I PET-guided lesional 3D dosimetry together with blood clearance studies can predict the absorbed lesion dose, improve selection of the safest and most effective ${ }^{131}$ I activity to administer, and predict responses to RAI treatment $(121,122)$. Nowadays, ${ }^{124}$ I PET is used almost exclusively in research settings owing to the limited availability of the tracer and the growing use of SPECT-CT for post-therapeutic ${ }^{131}$ I scan. ${ }^{18}$ F-Fluoride PET has been proposed for evaluating bone metastases from thyroid cancer, but the lytic nature of these lesions makes their evaluation difficult (123).

The performance of a new hybrid PET/MRI machine has recently been evaluated in thyroid cancer. Vrachimis et al. compared FDG PET/MRI with FDG PET/CT in DTC patients with detectable thyroglobulin production and found that the new method offered no diagnostic gains: recurrence detection rates were actually lower with FDG PET/MRI (85\% vs 97\% for FDG PET/CT) (124). Iodine $124 \mathrm{PET} / \mathrm{MRI}$ has also been used for lesion detection and dosimetry in high-risk thyroid cancer patients with lymph nodes metastases. The authors reported that MRI was superior to CT for identifying pathological lymph nodes, especially those smaller than $10 \mathrm{~mm}$ (125), but this issue requires further study.

\section{Conclusions}

The diagnostic imaging studies reviewed above play fundamental roles in post-treatment surveillance of patients with DTC. As in other settings, the key to success is selecting the proper tool(s) for the task at hand.

Figure 3 summarizes the current recommendations of the ATA for rational use of imaging studies during DTC follow-up assessments, including post-treatment staging and subsequent surveillance. The choice of first-line tools for this process may vary somewhat from center to center, depending on local resources. Cost and availability have to be considered. Studies available only in a few highly specialized centers may be useful in many patients, and depending on local resources, they may have a place in the first-line armamentarium (e.g. in a facility that includes a nuclear medicine department, WBS/SPECT-CT can be useful for routine use in several patient subsets). 
However, they are likely to be problematic for repeated use on patients being followed in facilities not located in metropolitan areas. Likewise, safety and tolerability are always valid concerns, but they play particularly important roles in ensuring patients' continuing participation in routine surveillance activities.

In the end, however, the final choice will be determined largely by the likelihood and probable location of persistent/recurrent disease and the sensitivity of the test for detecting this type of disease. In this context, the fact that over $85 \%$ of all thyroid cancers are PTCs $(126,127)$ is highly pertinent since these tumors spread via the lymphatics. One out of four PTC patients will develop cervical lymph node metastases (http://seer.cancer.gov/stat-facts/ html/thyro.html; last accessed 17 January 2016), whereas distant metastases are rare in PTC, particularly in the absence of cervical lymphadenopathy. Given its high sensitivity for thyroid bed and cervical lymph node lesions, its excellent safety and tolerability profiles, wide availability, and low cost, neck US is thus an ideal first-line imaging tool for use in almost all DTC patients and in almost all settings.

Second-line imaging studies are used more selectively and in cases where there is at least some reason to suspect metastasis (elevated or increasing levels of serum Tg, rising $\mathrm{Tg}$ antibody titers, atypical first-line imaging findings). The importance of specificity increases at the second-line level, and the higher risk status also justifies the use of methods that are most costly, less accessible, and/or more likely to be associated with some adverse effects.

\section{Declaration of interest}

The authors declare that there is no conflict of interest that could be perceived as prejudicing the impartiality of the research reported.

\section{Funding}

This work was supported by Umberto Di Mario Foundation ONLUS and Banca d'Italia.

\section{Acknowledgements}

Livia Lamartina is a fellow of PhD Program in 'Biomedical Technologies in Clinical Medicine' at the University of Rome Sapienza. The authors are grateful to Marian Everett Kent for her help in editing the manuscript.

\section{References}

1 Mazzaferri EL \& Jhiang SM. Long-term impact of initial surgical and medical therapy on papillary and follicular thyroid cancer. American Journal of Medicine 199497 418-428. (doi:10.1016/00029343(94)90321-2)

2 Mazzaferri EL \& Kloos RT. Clinical review 128: current approaches to primary therapy for papillary and follicular thyroid cancer.
Journal of Clinical Endocrinology and Metabolism 200186 1447-1463. (doi:10.1210/jcem.86.4.7407)

3 Durante C, Montesano T, Torlontano M, Attard M, Monzani F, Tumino S, Costante G, Meringolo D, Bruno R, Trulli F et al. Papillary thyroid cancer: time course of recurrences during postsurgery surveillance. Journal of Clinical Endocrinology and Metabolism 201398 636-642. (doi:10.1210/jc.2012-3401)

4 Davies L, Ouellette M, Hunter M \& Welch HG. The increasing incidence of small thyroid cancers: where are the cases coming from? Laryngoscope 2010120 2446-2451. (doi:10.1002/lary.v120:12)

5 Sosa JA, Hanna JW, Robinson KA \& Lanman RB. Increases in thyroid nodule fine-needle aspirations, operations, and diagnoses of thyroid cancer in the United States. Surgery 2013154 1420-1426. (doi:10.1016/j.surg.2013.07.006)

6 Davies L, Morris LG, Haymart M, Chen AY, Goldenberg D, Morris J, Ogilvie JB, Terris DJ, Netterville J, Wong RJ et al. American Association of Clinical Endocrinologists and American College of Endocrinology disease state clinical review: the increasing incidence of thyroid cancer. Endocrine Practice 201521 686-696. (doi:10.4158/ EP14466.DSCR)

7 Ito Y, Miyauchi A, Inoue H, Fukushima M, Kihara M, Higashiyama T, Tomoda C, Takamura Y, Kobayashi K \& Miya A. An observational trial for papillary thyroid microcarcinoma in Japanese patients. World Journal of Surgery 201034 28-35. (doi:10.1007/s00268-009-0303-0)

8 Sugitani I, Toda K, Yamada K, Yamamoto N, Ikenaga M \& Fujimoto Y. Three distinctly different kinds of papillary thyroid microcarcinoma should be recognized: our treatment strategies and outcomes. World Journal of Surgery 201034 1222-1231. (doi:10.1007/s00268-009-0359-x)

9 Haugen BR, Alexander EK, Bible KC, Doherty GM, Mandel SJ, Nikiforov YE, Pacini F, Randolph GW, Sawka AM, Schlumberger M et al. 2015 American Thyroid Association Management Guidelines for Adult Patients with Thyroid Nodules and Differentiated Thyroid Cancer: The American Thyroid Association Guidelines Task Force on Thyroid Nodules and Differentiated Thyroid Cancer. Thyroid 201626 1-133. (doi:10.1089/thy.2015.0020)

10 Wiebel JL, Banerjee M, Muenz DG, Worden FP \& Haymart MR. Trends in imaging after diagnosis of thyroid cancer. Cancer 2015121 1387-1394. (doi:10.1002/cncr.29210)

11 Lang K, Huang H, Lee DW, Federico V \& Menzin J. National trends in advanced outpatient diagnostic imaging utilization: an analysis of the medical expenditure panel survey, 2000-2009. BMC Medical Imaging 201313 40. (doi:10.1186/1471-2342-13-40)

12 Leenhardt L, Erdogan MF, Hegedus L, Mandel SJ, Paschke R, Rago T \& Russ G. European thyroid association guidelines for cervical ultrasound scan and ultrasound-guided techniques in the postoperative management of patients with thyroid cancer. European Thyroid Journal 20132 147-159. (doi:10.1159/000354537)

13 DeKay ML \& Asch DA. Is the defensive use of diagnostic tests good for patients, or bad? Medical Decision Making 199818 19-28. (doi:10.1177/ 0272989X9801800105)

14 Momesso DP \& Tuttle RM. Update on differentiated thyroid cancer staging. Endocrinology and Metabolism Clinics of North America 201443 401-421. (doi:10.1016/j.ecl.2014.02.010)

15 Fish SA, Langer JE \& Mandel SJ. Sonographic imaging of thyroid nodules and cervical lymph nodes. Endocrinology and Metabolism Clinics of North America 200837 401-417. (doi:10.1016/j. ecl.2007.12.003)

16 Pacini F, Molinaro E, Castagna MG, Agate L, Elisei R, Ceccarelli C, Lippi F, Taddei D, Grasso L \& Pinchera A. Recombinant human thyrotropin-stimulated serum thyroglobulin combined with neck ultrasonography has the highest sensitivity in monitoring differentiated thyroid carcinoma. Journal of Clinical Endocrinology and Metabolism 200388 3668-3673. (doi:10.1210/jc.2002-021925)

17 Torlontano M, Crocetti U, D'Aloiso L, Bonfitto N, Di Giorgio A, Modoni S, Valle G, Frusciante V, Bisceglia M, Filetti S et al. Serum thyroglobulin and 131I whole body scan after recombinant 
human TSH stimulation in the follow-up of low-risk patients with differentiated thyroid cancer. European Journal of Endocrinology 2003 148 19-24. (doi:10.1530/eje.0.1480019)

18 Torlontano M, Attard M, Crocetti U, Tumino S, Bruno R, Costante G, D'Azzò G, Meringolo D, Ferretti E, Sacco R et al. Follow-up of low risk patients with papillary thyroid cancer: role of neck ultrasonography in detecting lymph node metastases. Journal of Clinical Endocrinology and Metabolism 200489 3402-3407. (doi:10.1210/jc.2003-031521)

19 Durante C \& Filetti S. Management of papillary thyroid cancer patients in absence of postoperative radioiodine remnant ablation: tailoring follow-up by neck sonography. Journal of Clinical Endocrinology and Metabolism 201196 3059-3061. (doi:10.1210/jc.2011-1379)

20 Cooper DS, Doherty GM, Haugen BR, Kloos RT, Lee SL, Mandel SJ, Mazzaferri EL, McIver B, Sherman SI \& Tuttle RM. American Thyroid Association Guidelines Taskforce. Management guidelines for patients with thyroid nodules and differentiated thyroid cancer. Thyroid 2006 16 109-142. (doi:10.1089/thy.2006.16.109)

21 Aygun N. Imaging of recurrent thyroid cancer. Otolaryngologic Clinics of North America 200841 1095-1106.

22 Grani G \& Fumarola A. Thyroglobulin in lymph node fine-needle aspiration washout: a systematic review and meta-analysis of diagnostic accuracy. Journal of Clinical Endocrinology and Metabolism 201499 1970-1982. (doi:10.1210/jc.2014-1098)

23 Jeon MJ, Kim WG, Jang EK, Choi YM, Lee YM, Sung TY, Yoon JH, Chung KW, Hong SJ, Baek JH et al. Thyroglobulin level in fine-needle aspirates for preoperative diagnosis of cervical lymph node metastasis in patients with papillary thyroid carcinoma: two different cutoff values according to serum thyroglobulin level. Thyroid $2015 \mathbf{2 5}$ 410-416. (doi:10.1089/thy.2014.0544)

24 Jo K, Kim MH, Lim Y, Jung SL, Bae JS, Jung CK, Kang MI, Cha BY $\&$ Lim DJ. Lowered cutoff of lymph node fine-needle aspiration thyroglobulin in thyroid cancer patients with serum antithyroglobulin antibody. European Journal of Endocrinology 2015173 489-497. (doi:10.1530/EJE-15-0344)

25 Arturi F, Russo D, Giuffrida D, Ippolito A, Perrotti N, Vigneri R $\&$ Filetti S. Early diagnosis by genetic analysis of differentiated thyroid cancer metastases in small lymph nodes. Journal of Clinical Endocrinology and Metabolism 199782 1638-1641. (doi:10.1210/ jcem.82.5.4062)

26 Leboulleux S, Borget I, Labro S, Bidault S, Vielh P, Hartl D, Dauchy S, Chougnet CN, Girard E, Azoulay S et al. Frequency and intensity of pain related to thyroid nodule fine-needle aspiration cytology. Thyroid 201323 1113-1118. (doi:10.1089/thy.2012.0461)

27 Lang BH, Lee GC, Ng CP, Wong KP, Wan KY \& Lo CY. Evaluating the morbidity and efficacy of reoperative surgery in the central compartment for persistent/recurrent papillary thyroid carcinoma. World Journal of Surgery 201337 2853-2859. (doi:10.1007/s00268-0132202-7)

28 Onkendi EO, McKenzie TJ, Richards ML, Farley DR, Thompson GB Kasperbauer JL, Hay ID \& Grant CS. Reoperative experience with papillary thyroid cancer. World Journal of Surgery 201438 645-652. (doi:10.1007/s00268-013-2379-9)

29 Moreno MA, Edeiken-Monroe BS, Siegel ER, Sherman SI \& Clayman GL. In papillary thyroid cancer, preoperative central neck ultrasound detects only macroscopic surgical disease, but negative findings predict excellent long-term regional control and survival. Thyroid 201222 347-355. (doi:10.1089/thy.2011.0121)

30 Ito Y, Tomoda C, Uruno T, Takamura Y, Miya A, Kobayashi K, Matsuzuka F, Kuma K \& Miyauchi A. Ultrasonographically and anatomopathologically detectable node metastases in the lateral compartment as indicators of worse relapse-free survival in patients with papillary thyroid carcinoma. World Journal of Surgery 200529 917-920. (doi:10.1007/s00268-005-7789-x)

31 Ito Y, Tomoda C, Uruno T, Takamura Y, Miya A, Kobayashi K, Matsuzuka F, Kuma K \& Miyauchi A. Clinical significance of metastasis to the central compartment from papillary microcarcinoma of the thyroid. World Journal of Surgery 200630 91-99. (doi:10.1007/ s00268-005-0113-y)

32 Lepoutre-Lussey C, Maddah D, Golmard JL, Russ G, Tissier F, Trésallet C, Menegaux F, Aurengo A \& Leenhardt L. Post-operative neck ultrasound and risk stratification in differentiated thyroid cancer patients with initial lymph node involvement. European Journal of Endocrinology 2014170 837-846. (doi:10.1530/EJE-13-0888)

33 Frates MC. Ultrasound in recurrent thyroid disease. Otolaryngologic Clinics of North America 200841 1107-1116.

34 Lee JH, Lee HK, Lee DH, Choi CG, Gong G, Shong YK \& Kim SJ. Ultrasonographic findings of a newly detected nodule on the thyroid bed in postoperative patients for thyroid carcinoma: correlation with the results of ultrasonography-guided fine-needle aspiration biopsy. Clinical Imaging 200731 109-113. (doi:10.1016/j. clinimag.2006.11.001)

35 Wienke JR, Chong WK, Fielding JR, Zou KH \& Mittelstaedt CA Sonographic features of benign thyroid nodules: interobserver reliability and overlap with malignancy. Journal of Ultrasound in Medicine 200322 1027-1031.

36 Shin JH, Han BK, Ko EY \& Kang SS. Sonographic findings in the surgical bed after thyroidectomy: comparison of recurrent tumors and nonrecurrent lesions. Journal of Ultrasound in Medicine 200726 1359-1366.

37 Rondeau G, Fish S, Hann LE, Fagin JA \& Tuttle RM. Ultrasonographically detected small thyroid bed nodules identified after total thyroidectomy for differentiated thyroid cancer seldom show clinically significant structural progression. Thyroid 201121 845-853. (doi:10.1089/thy.2011.0011)

38 Leboulleux S, Girard E, Rose M, Travagli JP, Sabbah N, Caillou B, Hartl DM, Lassau N, Baudin E \& Schlumberger M. Ultrasound criteria of malignancy for cervical lymph nodes in patients followed up for differentiated thyroid cancer. Journal of Clinical Endocrinology and Metabolism 200792 3590-3594. (doi:10.1210/jc.2007-0444)

39 Kuna SK, Bracic I, Tesic V, Kuna K, Herceg GH \& Dodig D. Ultrasonographic differentiation of benign from malignant neck lymphadenopathy in thyroid cancer. Journal of Ultrasound in Medicine 200625 1531-1537.

40 Loevner LA. Thyroid and parathyroid glands: imaging, treatment and beyond. Preface. Neuroimaging Clinics of North America 200818 xiii-xiv.

41 Robenshtok E, Fish S, Bach A, Domínguez JM, Shaha A \& Tuttle RM. Suspicious cervical lymph nodes detected after thyroidectomy for papillary thyroid cancer usually remain stable over years in properly selected patients. Journal of Clinical Endocrinology and Metabolism 2012 97 2706-2713. (doi:10.1210/jc.2012-1553)

42 Lee J, Park JH, Lee CR, Chung WY \& Park CS. Long-term outcomes of total thyroidectomy versus thyroid lobectomy for papillary thyroid microcarcinoma: comparative analysis after propensity score matching. Thyroid 201323 1408-1415. (doi:10.1089/thy.2012.0463)

43 Matsuzu K, Sugino K, Masudo K, Nagahama M, Kitagawa W, Shibuya H, Ohkuwa K, Uruno T, Suzuki A, Magoshi S et al. Thyroid lobectomy for papillary thyroid cancer: long-term follow-up study of 1,088 cases. World Journal of Surgery 201438 68-79. (doi:10.1007/ s00268-013-2224-1)

44 Durante C, Montesano T, Attard M, Torlontano M, Monzani F, Costante G, Meringolo D, Ferdeghini M, Tumino S, Lamartina L et al. Long-term surveillance of papillary thyroid cancer patients who do not undergo postoperative radioiodine remnant ablation: is there a role for serum thyroglobulin measurement? Journal of Clinical Endocrinology and Metabolism 201297 2748-2753. (doi:10.1210/ jc.2012-1123)

45 Angell TE, Spencer CA, Rubino BD, Nicoloff JT \& LoPresti JS. In search of an unstimulated thyroglobulin baseline value in low-risk papillary thyroid carcinoma patients not receiving radioactive iodine ablation. Thyroid 201424 1127-1133. (doi:10.1089/thy.2013.0691)

46 Rosario PW, Mourão GF, Siman TL \& Calsolari MR. Serum thyroglobulin measured with a second-generation assay in patients undergoing total 
thyroidectomy without radioiodine remnant ablation: a prospective study. Thyroid 201525 769-775. (doi:10.1089/thy.2014.0496)

47 Momesso DP, Vaisman F, Yang SP, Bulzico DA, Corbo R, Vaisman M $\&$ Tuttle RM. Dynamic risk stratification in differentiated thyroid cancer patients treated without radioactive iodine. Journal of Clinical Endocrinology and Metabolism 2016. (doi:10.1210/jc.2015-4290)

48 Durante C, Attard M, Torlontano M, Ronga G, Monzani F, Costante G, Ferdeghini M, Tumino S, Meringolo D, Bruno R et al. Identification and optimal postsurgical follow-up of patients with very low-risk papillary thyroid microcarcinomas. Journal of Clinical Endocrinology and Metabolism 201095 4882-4888. (doi:10.1210/ jc.2010-0762)

49 Peiling Yang S, Bach AM, Tuttle RM \& Fish SA. Frequent screening with serial neck ultrasound is more likely to identify false-positive abnormalities than clinically significant disease in the surveillance of intermediate risk papillary thyroid cancer patients without suspicious findings on follow-up ultrasound evaluation. Journal of Clinical Endocrinology and Metabolism 2015100 1561-1567. (doi:10.1210/ jc.2014-3651)

50 Wang LY, Roman BR, Palmer FL, Tuttle RM, Shaha AR, Shah JP, Patel SG \& Ganly I. Effectiveness of routine ultrasonographic surveillance of patients with low-risk papillary carcinoma of the thyroid. Surgery 2016159 1390-1395. (doi:10.1016/j. surg.2015.11.018)

51 Pitoia F, Abelleira E, Tala H, Bueno F, Urciuoli C \& Cross G. Biochemical persistence in thyroid cancer: is there anything to worry about? Endocrine 201446 532-537. (doi:10.1007/s12020-013-0097-6)

52 Eisenhauer EA, Therasse P, Bogaerts J, Schwartz LH, Sargent D, Ford R, Dancey J, Arbuck S, Gwyther S, Mooney M et al. New response evaluation criteria in solid tumours: revised RECIST guideline (version 1.1). European Journal of Cancer 200945 228-247. (doi:10.1016/j. ejca.2008.10.026)

53 Einstein AJ, Henzlova MJ \& Rajagopalan S. Estimating risk of cancer associated with radiation exposure from 64-slice computed tomography coronary angiography. JAMA 200718 317-323. (doi:10.1001/jama.298.3.317)

54 Wang JC, Takashima S, Takayama F, Kawakami S, Saito A, Matsushita T, Matsuba H \& Kobayashi S. Tracheal invasion by thyroid carcinoma: prediction using MR imaging. AJR. American Journal of Roentgenology 2001177 929-936. (doi:10.2214/ajr.177.4.1770929)

55 Wang J, Takashima S, Matsushita T, Takayama F, Kobayashi T \& Kadoya M. Esophageal invasion by thyroid carcinomas: prediction using magnetic resonance imaging. Journal of Computer Assisted Tomography 200327 18-25. (doi:10.1097/00004728-200301000-00004)

56 Gross ND, Weissman JL, Talbot JM, Andersen PE, Wax MK \& Cohen JI. MRI detection of cervical metastasis from differentiated thyroid carcinoma. Laryngoscope 2001111 1905-1909.

57 Toubert ME, Cyna-Gorse F, Zagdanski AM, Noel-Wekstein S, Cattan P, Billotey C, Sarfati E \& Rain JD. Cervicomediastinal magnetic resonance imaging in persistent or recurrent papillary thyroid carcinoma: clinical use and limits. Thyroid 19999 591-597. (doi:10.1089/thy.1999.9.591)

58 Muresan MM, Olivier P, Leclère J, Sirveaux F, Brunaud L, Klein M, Zarnegar R \& Weryha G. Bone metastases from differentiated thyroid carcinoma. Endocrine-Related Cancer 200815 37-49. (doi:10.1677/ ERC-07-0229)

59 Schmidt GP, Schoenberg SO, Schmid R, Stahl R, Tiling R, Becker CR, Reiser MF \& Baur-Melnyk A. Screening for bone metastases: wholebody MRI using a 32-channel system versus dual-modality PET-CT. European Radiology 200717 939-949. (doi:10.1007/s00330-006-0361-8)

60 Sakurai Y, Kawai H, Iwano S, Ito S, Ogawa H \& Naganawa S. Supplemental value of diffusion-weighted whole-body imaging with background body signal suppression (DWIBS) technique to whole-body magnetic resonance imaging in detection of bone metastases from thyroid cancer. Journal of Medical Imaging and Radiation Oncology 201357 297-305. (doi:10.1111/jmiro.2013.57.issue-3)
61 Schellinger PD, Meinck HM \& Thron A. Diagnostic accuracy of MRI compared to CCT in patients with brain metastases. Journal of NeuroOncology 199944 275-281. (doi:10.1023/A:1006308808769)

62 Salvatori M, Perotti G, Rufini V, Maussier ML, Summaria V, Fadda G \& Troncone L. Solitary liver metastasis from Hürthle cell thyroid cancer: a case report and review of the literature. Journal of Endocrinological Investigation 200427 52-56.

63 Giraudet AL, Vanel D, Leboulleux S, Aupérin A, Dromain C, Chami L, Ny Tovo N, Lumbroso J, Lassau N, Bonniaud G et al. Imaging medullary thyroid carcinoma with persistent elevated calcitonin levels. Journal of Clinical Endocrinology and Metabolism 200792 4185-4190. (doi:10.1210/jc.2007-1211)

64 Dromain C, de Baere T, Lumbroso J, Caillet H, Laplanche A, Boige V, Ducreux M, Duvillard P, Elias D, Schlumberger M et al. Detection of liver metastases from endocrine tumors: a prospective comparison of somatostatin receptor scintigraphy, computed tomography, and magnetic resonance imaging. Journal of Clinical Oncology 20051 70-78.

65 Arturi F, Russo D, Schlumberger M, du Villard JA, Caillou B, Vigneri P, Wicker R, Chiefari E, Suarez HG \& Filetti S. Iodide symporter gene expression in human thyroid tumors. Journal of Clinical Endocrinology and Metabolism 199883 2493-2496. (doi:10.1210/jcem.83.7.4974)

66 Arturi F, Russo D, Giuffrida D, Schlumberger M \& Filetti S. Sodiumiodide symporter (NIS) gene expression in lymph-node metastases of papillary thyroid carcinomas. European Journal of Endocrinology 2000 143 623-627. (doi:10.1530/eje.0.1430623)

67 Schlumberger M, Lacroix L, Russo D, Filetti S \& Bidart JM. Defects in iodide metabolism in thyroid cancer and implications for the follow-up and treatment of patients. Nature Clinical Practice Endocrinology and Metabolism 20073 260-269. (doi:10.1038/ncpendmet0449)

68 Trapasso F, Iuliano R, Chiefari E, Arturi F, Stella A, Filetti S, Fusco A $\&$ Russo D. Iodide symporter gene expression in normal and transformed rat thyroid cells. European Journal of Endocrinology 1999 140 447-451. (doi:10.1530/eje.0.1400447)

69 Durante C, Puxeddu E, Ferretti E, Morisi R, Moretti S, Bruno R, Barbi F, Avenia N, Scipioni A, Verrienti A et al. BRAF mutations in papillary thyroid carcinomas inhibit genes involved in iodine metabolism. Journal of Clinical Endocrinology and Metabolism 200792 2840-2843. (doi:10.1210/jc.2006-2707)

70 Lubin E, Mechlis-Frish S, Zatz S, Shimoni A, Segal K, Avraham A, Levy R \& Feinmesser R. Serum thyroglobulin and iodine-131 wholebody scan in the diagnosis and assessment of treatment for metastatic differentiated thyroid carcinoma. Journal of Nuclear Medicine 199435 257-262.

71 Franceschi M, Kusić Z, Franceschi D, Lukinac L \& Roncević S. Thyroglobulin determination, neck ultrasonography and iodine-131 whole-body scintigraphy in differentiated thyroid carcinoma. Journal of Nuclear Medicine 199637 446-451.

72 Filesi M, Signore A, Ventroni G, Melacrinis FF \& Ronga G. Role of initial iodine-131 whole-body scan and serum thyroglobulin in differentiated thyroid carcinoma metastases. Journal of Nuclear Medicine 199839 1542-1546.

73 Mazzaferri EL \& Kloos RT. Is diagnostic iodine-131 scanning with recombinant human TSH useful in the follow-up of differentiated thyroid cancer after thyroid ablation? Journal of Clinical Endocrinology and Metabolism 200287 1490-1498. (doi:10.1210/jcem.87.4.8338)

74 Pacini F, Ladenson PW, Schlumberger M, Driedger A, Luster M, Kloos RT, Sherman S, Haugen B, Corone C, Molinaro E et al. Radioiodine ablation of thyroid remnants after preparation with recombinant human thyrotropin in differentiated thyroid carcinoma: results of an international, randomized, controlled study. Journal of Clinical Endocrinology and Metabolism 200691 926-932. (doi:10.1210/ jc.2005-1651)

75 Rosario PW, Xavier AC \& Calsolari MR. Value of postoperative thyroglobulin and ultrasonography for the indication of ablation and ${ }^{131}$ I activity in patients with thyroid cancer and low risk of recurrence. Thyroid 201121 49-53. (doi:10.1089/thy.2010.0145) 
76 Elisei R, Molinaro E, Agate L, Bottici V, Masserini L, Ceccarelli C, Lippi F, Grasso L, Basolo F, Bevilacqua G et al. Are the clinical and pathological features of differentiated thyroid carcinoma really changed over the last 35 years? Study on 4187 patients from a single Italian institution to answer this question. Journal of Clinical Endocrinology and Metabolism 201095 1516-1527. (doi:10.1210/jc.2009-1536)

77 Goffredo P, Sosa JA \& Roman SA. Differentiated thyroid cancer presenting with distant metastases: a population analysis over two decades. World Journal of Surgery 201337 1599-1605. (doi:10.1007/ s00268-013-2006-9)

78 Pacini F, Capezzone M, Elisei R, Ceccarelli C, Taddei D \& Pinchera A. Diagnostic 131-iodine whole-body scan may be avoided in thyroid cancer patients who have undetectable stimulated serum Tg levels after initial treatment. Journal of Clinical Endocrinology and Metabolism 200287 1499-1501. (doi:10.1210/jcem.87.4.8274)

79 de Meer SG, Vriens MR, Zelissen PM, Borel Rinkes IH \& de Keizer B. The role of routine diagnostic radioiodine whole-body scintigraphy in patients with high-risk differentiated thyroid cancer. Journal of Nuclear Medicine 201152 56-59. (doi:10.2967/jnumed.110.080697)

80 Rosario PW, Furtado Mde S, Mineiro Filho AF, Lacerda RX \& Calsolari MR. Value of diagnostic radioiodine whole-body scanning after initial therapy in patients with differentiated thyroid cancer at intermediate and high risk for recurrence. Thyroid 201222 1165-1169. (doi:10.1089/thy.2012.0026)

81 Jeon EJ \& Jung ED. Diagnostic whole-body scan may not be necessary for intermediate-risk patients with differentiated thyroid cancer after low-dose $(30 \mathrm{mCi})$ radioactive iodide ablation. Endocrinology and Metabolism 201429 33-39. (doi:10.3803/EnM.2014.29.1.33)

82 Van Nostrand D, Aiken M, Atkins F, Moreau S, Garcia C, Acio E, Burman K \& Wartofsky L. The utility of radioiodine scans prior to iodine 131 ablation in patients with well-differentiated thyroid cancer. Thyroid 200919 849-855. (doi:10.1089/thy.2008.0419)

83 Yin Y, Mao Q, Chen S, Li N, Li X \& Li Y. A clinical trial of optimal time interval between ablation and diagnostic activity when a pretherapy RAI scanning is performed on patients with differentiated thyroid carcinoma. Medicine 201594 e1308. (doi:10.1097/ MD.0000000000001308)

84 Yap BK \& Murby B. No adverse affect in clinical outcome using low preablation diagnostic (131)i activity in differentiated thyroid cancer: refuting thyroid-stunning effect. Journal of Clinical Endocrinology and Metabolism 201499 2433-2440. (doi:10.1210/jc.2014-1405)

85 Mandel SJ, Shankar LK, Benard F, Yamamoto A \& Alavi A. Superiority of iodine-123 compared with iodine-131 scanning for thyroid remnants in patients with differentiated thyroid cancer. Clinical Nuclear Medicine 200126 6-9. (doi:10.1097/00003072-200101000-00002)

86 Urhan M, Dadparvar S, Mavi A, Houseni M, Chamroonrat W, Alavi A \& Mandel SJ. Iodine-123 as a diagnostic imaging agent in differentiated thyroid carcinoma: a comparison with iodine-131 posttreatment scanning and serum thyroglobulin measurement. European Journal of Nuclear Medicine and Molecular Imaging 200734 1012-1017. (doi:10.1007/s00259-006-0341-x)

87 Chen MK, Yasrebi M, Samii J, Staib LH, Doddamane I \& Cheng DW. The utility of I-123 pretherapy scan in I-131 radioiodine therapy for thyroid cancer. Thyroid 201222 304-309. (doi:10.1089/ thy.2011.0203)

88 Hänscheid H, Lassmann M, Buck AK, Reiners C \& Verburg FA. The limit of detection in scintigraphic imaging with I-131 in patients with differentiated thyroid carcinoma. Physics in Medicine and Biology 2014 59 2353-2368. (doi:10.1088/0031-9155/59/10/2353)

89 Hay ID, Thompson GB, Grant CS, Bergstralh EJ, Dvorak CE, Gorman CA, Maurer MS, McIver B, Mullan BP, Oberg AL et al. Papillary thyroid carcinoma managed at the Mayo Clinic during six decades (1940-1999): temporal trends in initial therapy and long-term outcome in 2444 consecutively treated patients. World Journal of Surgery 200226 879-885. (doi:10.1007/s00268002-6612-1)
90 Oh JR \& Ahn BC. False-positive uptake on radioiodine whole-body scintigraphy: physiologic and pathologic variants unrelated to thyroid cancer. American Journal of Nuclear Medicine and Molecular Imaging 20122 362-385.

91 Xing M, Haugen BR \& Schlumberger M. Progress in molecularbased management of differentiated thyroid cancer. Lancet 201323 1058-1069.

92 Durante C, Haddy N, Baudin E, Leboulleux S, Hartl D, Travagli JP, Caillou B, Ricard M, Lumbroso JD, De Vathaire F et al. Long-term outcome of 444 patients with distant metastases from papillary and follicular thyroid carcinoma: benefits and limits of radioiodine therapy. Journal of Clinical Endocrinology and Metabolism 200691 2892-2899. (doi:10.1210/jc.2005-2838)

93 Barwick T, Murray I, Megadmi H, Drake WM, Plowman PN, Akker SA, Chew SL, Grossman AB \& Avril N. Single photon emission computed tomography (SPECT)/computed tomography using Iodine-123 in patients with differentiated thyroid cancer: additional value over whole body planar imaging and SPECT. European Journal of Endocrinology 2010162 1131-1139. (doi:10.1530/EJE-09-1023)

94 Tharp K, Israel O, Hausmann J, Bettman L, Martin WH, Daitzchman M, Sandler MP \& Delbeke D. Impact of 131I-SPECT/ CT images obtained with an integrated system in the follow-up of patients with thyroid carcinoma. European Journal of Nuclear Medicine and Molecular Imaging 200431 1435-1442. (doi:10.1007/s00259-0041565-2)

95 Aide N, Heutte N, Rame JP, Rousseau E, Loiseau C, Henry-Amar M $\&$ Bardet $\mathrm{S}$. Clinical relevance of single-photon emission computed tomography/computed tomography of the neck and thorax in postablation (131)I scintigraphy for thyroid cancer. Journal of Clinical Endocrinology and Metabolism 200994 2075-2084. (doi:10.1210/ jc.2008-2313)

96 Schmidt D, Szikszai A, Linke R, Bautz W \& Kuwert T. Impact of 131I SPECT/spiral CT on nodal staging of differentiated thyroid carcinoma at the first radioablation. Journal of Nuclear Medicine 2009 50 18-23. (doi:10.2967/jnumed.108.052746)

97 Spanu A, Solinas ME, Chessa F, Sanna D, Nuvoli S \& Madeddu G. 131I SPECT/CT in the follow-up of differentiated thyroid carcinoma: incremental value versus planar imaging. Journal of Nuclear Medicine 200950 184-190. (doi:10.2967/jnumed.108.056572)

98 Jeong SY, Lee SW, Kim HW, Song BI, Ahn BC \& Lee J. Clinical applications of SPECT/CT after first I-131 ablation in patients with differentiated thyroid cancer. Clinical Endocrinology 201481 445-451. (doi:10.1111/cen.12460)

99 Dong MJ, Liu ZF, Zhao K, Ruan LX, Wang GL, Yang SY, Sun F \& Luo XG. Value of 18F-FDG-PET/PET-CT in differentiated thyroid carcinoma with radioiodine-negative whole-body scan: a metaanalysis. Nuclear Medicine Communications 200930 639-650. (doi:10.1097/MNM.0b013e32832dcfa7)

100 Caetano R, Bastos CR, de Oliveira I, da Silva RM, Fortes CP, Pepe VL, Reis LG \& Braga JU. Accuracy of positron emission tomography and positron emission tomography-CT in the detection of differentiated thyroid cancer recurrence with negative 131 I whole-body scan results: a meta-analysis. Head \& Neck 201638 316-327. (doi:10.1002/ hed.23881)

101 Giammarile F, Hafdi Z, Bournaud C, Janier M, Houzard C, Desuzinges C, Itti R, Sassolas G \& Borson-Chazot F. Is [18F]-2fluoro-2-deoxy-d-glucose (FDG) scintigraphy with non-dedicated positron emission tomography useful in the diagnostic management of suspected metastatic thyroid carcinoma in patients with no detectable radioiodine uptake. European Journal of Endocrinology 2003 149 293-300. (doi:10.1530/eje.0.1490293)

102 Leboulleux S, Schroeder PR, Busaidy NL, Auperin A, Corone C, Jacene HA, Ewertz ME, Bournaud C, Wahl RL, Sherman SI et al. Assessment of the incremental value of recombinant thyrotropin stimulation before 2-[18F]-Fluoro-2-deoxy-D-glucose positron emission tomography/computed tomography imaging to localize 
residual differentiated thyroid cancer. Journal of Clinical Endocrinology and Metabolism 200994 1310-1316. (doi:10.1210/jc.2008-1747)

103 Wiebel JL, Esfandiari NH, Papaleontiou M, Worden FP \& Haymart MR. Evaluating positron emission tomography use in differentiated thyroid cancer. Thyroid 201525 1026-1032. (doi:10.1089/thy.2015.0062)

104 Rivera M, Ghossein RA, Schoder H, Gomez D, Larson SM \& Tuttle RM. Histopathologic characterization of radioactive iodine-refractory fluorodeoxyglucose-positron emission tomography-positive thyroid carcinoma. Cancer 2008113 48-56. (doi:10.1002/cncr.235150)

105 Wang W, Larson SM, Tuttle RM, Kalaigian H, Kolbert K, Sonenberg M \& Robbins RJ. Resistance of [18f]-fluorodeoxyglucoseavid metastatic thyroid cancer lesions to treatment with high-dose radioactive iodine. Thyroid 200111 1169-1175. (doi:10.1089/10507250152741028)

106 Leboulleux S, El Bez I, Borget I, Elleuch M, Déandreis D, Al Ghuzlan A, Chougnet C, Bidault F, Mirghani H, Lumbroso J et al. Postradioiodine treatment whole-body scan in the era of 18-fluorodeoxyglucose positron emission tomography for differentiated thyroid carcinoma with elevated serum thyroglobulin levels. Thyroid 201222 832-838. (doi:10.1089/thy.2012.0081)

107 Lee JW, Lee SM, Lee DH \& Kim YJ. Clinical utility of 18F-FDG PET/ CT concurrent with 131I therapy in intermediate-to-high-risk patients with differentiated thyroid cancer: dual-center experience with 286 patients. Journal of Nuclear Medicine 201354 1230-1236. (doi:10.2967/jnumed.112.117119)

108 Nascimento C, Borget I, Al Ghuzlan A, Deandreis D, Hartl D, Lumbroso J, Berdelou A, Lepoutre-Lussey C, Mirghani H, Baudin E et al. Postoperative fluorine-18-fluorodeoxyglucose positron emission tomography/computed tomography: an important imaging modality in patients with aggressive histology of differentiated thyroid cancer. Thyroid 201525 437-444. (doi:10.1089/thy.2014.0320)

109 Schlüter B, Bohuslavizki KH, Beyer W, Plotkin M, Buchert R \& Clausen M. Impact of FDG PET on patients with differentiated thyroid cancer who present with elevated thyroglobulin and negative 131I scan. Journal of Nuclear Medicine 2001 42 71-76.

110 Giovanella L, Ceriani L, De Palma D, Suriano S, Castellani M \& Verburg FA. Relationship between serum thyroglobulin and 18FDGPET/CT in 131I-negative differentiated thyroid carcinomas. Head \& Neck 201234 626-631.

111 Giovanella L, Trimboli P, Verburg FA, Treglia G, Piccardo A, Foppiani L \& Ceriani L. Thyroglobulin levels and thyroglobulin doubling time independently predict a positive 18F-FDG PET/ CT scan in patients with biochemical recurrence of differentiated thyroid carcinoma. European Journal of Nuclear Medicine and Molecular Imaging 201340 874-880. (doi:10.1007/s00259-013-2370-6)

112 Grant CS, Thompson GB, Farley DR, Richards ML, Mullan BP \& Hay ID. The value of positron emission tomography in the surgical management of recurrent papillary thyroid carcinoma. World Journal of Surgery 200832 708-715. (doi:10.1007/s00268-007-9361-3)

113 Zoller M, Kohlfuerst S, Igerc I, Kresnik E, Gallowitsch HJ, Gomez I \& Lind P. Combined PET/CT in the follow-up of differentiated thyroid carcinoma: what is the impact of each modality. European Journal of Nuclear Medicine and Molecular Imaging 200734 487-495. (doi:10.1007/s00259-006-0276-2)

114 Ma C, Xie J, Lou Y, Gao Y, Zuo S \& Wang X. The role of TSH for 18F-FDG-PET in the diagnosis of recurrence and metastases of differentiated thyroid carcinoma with elevated thyroglobulin and negative scan: a meta-analysis. European Journal of Endocrinology 2010 163 177-183. (doi:10.1530/EJE-10-0256)

115 Deandreis D, Al Ghuzlan A, Leboulleux S, Lacroix L, Garsi JP, Talbot M, Lumbroso J, Baudin E, Caillou B, Bidart JM et al.
Do histological, immunohistochemical, and metabolic (radioiodine and fluorodeoxyglucose uptakes) patterns of metastatic thyroid cancer correlate with patient outcome? Endocrine-Related Cancer 2011 13 159-169. (doi:10.1677/ERC-10-0233)

116 Robbins RJ, Wan Q, Grewal RK, Reibke R, Gonen M, Strauss HW, Tuttle RM, Drucker W \& Larson SM. Real-time prognosis for metastatic thyroid carcinoma based on 2-[18F]fluoro-2-deoxy-D-glucose-positron emission tomography scanning. Journal of Clinical Endocrinology and Metabolism 200691 498-505. (doi:10.1210/jc.2005-1534)

117 Freudenberg LS, Antoch G, Jentzen W, Pink R, Knust J, Görges R, Müller SP, Bockisch A, Debatin JF \& Brandau W. Value of (124)I-PET/ $\mathrm{CT}$ in staging of patients with differentiated thyroid cancer. European Radiology 200414 2092-2098. (doi:10.1007/s00330-004-2350-0)

118 Phan HT, Jager PL, Paans AM, Plukker JT, Sturkenboom MG, Sluiter WJ, Wolffenbuttel BH, Dierckx RA \& Links TP. The diagnostic value of 124I-PET in patients with differentiated thyroid cancer. European Journal of Nuclear Medicine and Molecular Imaging 200835 958-965. (doi:10.1007/s00259-007-0660-6)

119 Van Nostrand D, Moreau S, Bandaru VV, Atkins F, Chennupati S, Mete M, Burman K \& Wartofsky L. (124)I positron emission tomography versus ( )I planar imaging in the identification of residual thyroid tissue and/or metastasis in patients who have well-differentiated thyroid cancer. Thyroid 201020 879-83. (doi:10.1089/thy.2009.0430)

120 Freudenberg LS, Jentzen W, Müller SP \& Bockisch A. Disseminated iodine-avid lung metastases in differentiated thyroid cancer: a challenge to 124I PET. European Journal of Nuclear Medicine and Molecular Imaging 200835 502-508. (doi:10.1007/s00259-007-0601-4)

121 Sgouros G, Kolbert KS, Sheikh A, Pentlow KS, Mun EF, Barth A, Robbins RJ \& Larson SM. Patient-specific dosimetry for 131I thyroid cancer therapy using 124I PET and 3-dimensional-internal dosimetry (3D-ID) software. Journal of Nuclear Medicine 200445 1366-1372.

122 Jentzen W, Hoppenbrouwers J, van Leeuwen P, van der Velden D, van de Kolk R, Poeppel TD, Nagarajah J, Brandau W, Bockisch A $\&$ Rosenbaum-Krumme S. Assessment of lesion response in the initial radioiodine treatment of differentiated thyroid cancer using 124I PET imaging. Journal of Nuclear Medicine 201455 1759-1765. (doi:10.2967/jnumed.114.144089)

123 Schirrmeister H, Buck A, Guhlmann A \& Reske SN. Anatomical distribution and sclerotic activity of bone metastases from thyroid cancer assessed with F-18 sodium fluoride positron emission tomography. Thyroid 200111 677-683. (doi:10.1089/105072501750 362754)

124 Vrachimis A, Burg MC, Wenning C, Allkemper T, Weckesser M, Schäfers M \& Stegger L. [18F]FDG PET/CT outperforms [18F]FDG PET/MRI in differentiated thyroid cancer. European Journal of Nuclear Medicine and Molecular Imaging 201643 212-220. (doi:10.1007/ s00259-015-3195-2)

125 Nagarajah J, Jentzen W, Hartung V, Rosenbaum-Krumme S, Mikat C, Heusner TA, Antoch G, Bockisch A \& Stahl A. Diagnosis and dosimetry in differentiated thyroid carcinoma using 124I PET: comparison of PET/MRI vs PET/CT of the neck. European Journal of Nuclear Medicine and Molecular Imaging 201138 1862-1868. (doi:10.1007/s00259-011-1866-1)

126 Brito JP, Al Nofal A, Montori VM, Hay ID \& Morris JC. The impact of subclinical disease and mechanism of detection on the rise in thyroid cancer incidence: a population-based study in Olmsted County, Minnesota during 1935 through 2012. Thyroid 201525 999-1007. (doi:10.1089/thy.2014.0594)

127 Bahl M, Sosa JA, Nelson RC, Esclamado RM, Choudhury KR \& Hoang JK. Trends in incidentally identified thyroid cancers over a decade: a retrospective analysis of 2,090 surgical patients. World Journal of Surgery 201438 1312-1317. (doi:10.1007/s00268-013-2407-9)

Received 31 January 2016

Revised version received 8 April 2016

Accepted 31 May 2016 